\title{
Algo anda ocurriendo: variación diatópica de andar + GERUNDIO ${ }^{1}$
}

\author{
Dorien Nieuwenhuijsen ${ }^{2}$ \\ Universidad de Utrecht, Holanda
}

\begin{abstract}
Resumen
El presente trabajo examina la variación diatópica de la perífrasis andar + GER, comparando su uso en el español mexicano con el uso peninsular. Para ello, se analiza la frecuencia relativa de la misma en varios corpus y se estudian sus rasgos semánticos y sintácticos más destacados. El análisis cuantitativo, por una parte, pone de manifiesto la mayor frecuencia de andar + GER en el español de México en comparación con el español peninsular. Por otra parte, revela que la perífrasis ocurre, sobre todo, en modalidades de lengua informales. En el plano semántico, el presente estudio confirma que, en perífrasis de gerundio, el verbo andar ha ido perdiendo su significado léxico de movimiento físico y ha llegado a transmitir valores pragmáticos, particularmente de determinación y empeño. Asimismo, a diferencia del español de España, en el español de México la perífrasis está sometida a relativamente pocas restricciones selectivas respecto del gerundio, evolución que se fecha en épocas relativamente recientes. En el nivel sintáctico, el proceso de gramaticalización se manifiesta en
\end{abstract}

\footnotetext{
1 El título se inspira en la siguiente cita: “..., pues los ascos no son una enfermedad en sí, sino el resultado de que algo anda ocurriendo en nuestro organismo" (https://www.imer. $\mathrm{mx} /$ tropicalisima/nauseas/).

2 Para correspondencia, dirigirse a: Dorien Nieuwenhuijsen (D.Nieuwenhuijsen@uu.nl), Universidad de Utrecht. Trans 10, 3512 JK Utrecht, Holanda.
} 
la adyacencia del auxiliar y el gerundio, el orden interno fijo de los dos componentes de la perífrasis, la subida de clíticos y la disminución de gerundios coordinados. El caso de andar + GER demuestra que la gramaticalización de una misma construcción puede desarrollarse de manera diferente según el entorno específico dialectal. Al mismo tiempo y en un nivel más general, realza la importancia del enfoque diatópico en los estudios sobre las perífrasis verbales y los procesos de gramaticalización.

Palabras clave: perífrasis verbal, andar + GERUNDIO, español de México, semántica, gramaticalización, gramática de construcciones.

ALGO ANDA OCURRIENDO: DIATOPIC VARIATION OF ANDAR + GERUND

\begin{abstract}
This paper examines the diatopic variation of the periphrasis andar + GER, comparing its use in Mexican and Peninsular Spanish. To this end, the relative frequency of the construction is analyzed in several corpora, as well as its most distinctive semantic and syntactic features. Our quantitative analysis shows, on the one hand, the high frequency of andar + GER in Mexican Spanish as compared to Peninsular Spanish. On the other hand, it reveals that the periphrasis occurs, above all, in informal language modalities. Semantically, the present study corroborates that, in periphrases with a gerund, the verb andar ('to walk'), has progressively lost its lexical meaning of physical movement and has come to transmit pragmatic values, particularly of determination and insistence. In addition, unlike Peninsular Spanish, in Mexican Spanish the periphrasis is less subject to selectional restrictions with respect to the gerund, a relatively recent change that points to a strong grammaticalization. Syntactically, the grammaticalization process is reflected in the adjacency of the auxiliary and the gerund, the fixed internal order of the two components of the periphrasis, clitic climbing and a drop in the frequency of coordinated gerunds. The case of andar + GER demonstrates that grammaticalization of the same construction can take place in different ways depending on the specific dialectal environment. Likewise, and at a more general level, it stresses the importance of a diatopic approach in studies on verbal periphrases and grammaticalization processes.
\end{abstract}

Keywords: verbal periphrasis, andar + GERUND, Mexican Spanish, semantics, grammaticalization, construction grammar.

Recibido: 05/06/19 Aceptado:02/08/19 


\section{INTRODUCCIÓN}

En el marco de los trabajos sobre las perífrasis verbales en español, la de andar ha recibido considerable atención por ser una de las más prototípicas, si por perífrasis se entiende una combinación de varias palabras que expresan una distinción semántica adicional (Haspelmath 2000: 656) o se define, de acuerdo con Olbertz (1998: 32), como "the productive and indissoluble combination of an auxiliarized lexical verb with a verbal predicate in a specific no-finite form in which the finite verb agrees with the first argument of the non-finite verb".

La construcción andar + GER pertenece, por una parte, al grupo de perífrasis cuya forma infinita es un gerundio, del que forman parte también, entre otras, las perífrasis con seguir, llevar y acabar (cf. Camus Bergareche 2004; Fente, Fernández y Feijóo 1972; Fernández de Castro 2003; García Fernández 2006; García González 1992; Gómez Torrego 1988; Hamplová 1968; Keniston 1937; Lyer 1932; 1934; Markič 2006; Matthies 1933; Morera 1991; Olbertz 1998; Porroche Ballesteros 1990; RAE y ASALE 2009: 2185 y ss.; Roca Pons 1958; Sarrazin 2011; Squartini 1998; Torres Cacoullos 1999a; 2000; 2001; 2012; Yllera 1980; 1999). Por otra parte, andar + GER se inserta en el grupo de perífrasis formadas a partir de un verbo de movimiento, que resulta ser una clase de verbos muy productiva en lo que concierne a la creación de perífrasis (p.e. ir a + INF; ir + GER; venir $a+\mathrm{INF}$; llegar $a+\mathrm{INF}$; salir + GER; Cf. Alonso 1951; Coseriu 1977; Crego García 1994; Markič 2006; Roca Pons 1958; Sarrazin 2011; Squartini 1998: 207 y ss.).

Suele caracterizarse la perífrasis andar + GER como frecuentativa o (re) iterativa (Camus Bergareche 2004: 553; Fernández de Castro 1999: 329; 2003: 21; García Fernández 2006: 87; 2012: 70; Gómez Torrego 1988: 149; Hamplová 1968: 226, 227; Llorente Vigil 1999: 56; Roca Pons 1958: 13, 66). La RAE y la ASALE (2009: 2198) precisan que la misma "describe situaciones que se desarrollan con interrupciones o de modo intermitente", en tanto que Olbertz (1998: 285, 372) le atribuye un valor distributivo, es decir, que expresa que "some event takes place several times at different occasions and/or with different participants".

Por el momento, dejamos la discusión del valor preciso de la perífrasis para más adelante y nos limitamos a presentar los ejemplos (1) y (2), que son ilustrativos para su uso actual.

(1) Siempre nos andan diciendo que deberíamos estar contentos de tener comida y todo eso, ... (Eric Hobsbawm, Historia del siglo XX, 1995, Gradia) 
(2) ¿No ves que es eso lo que anda buscando, con tanto contarte su vida? (Rafael Sánchez Ferlosio, El Jarama, 1956, GrADIA)

Los estudios sobre la perífrasis citados antes no suelen mencionar diferencias diatópicas, y la mayor parte parece centrarse en el uso de andar + GER en el español peninsular. Sin embargo, hay indicios de que su frecuencia - particularmente alta en México- muestra variación dialectal (cf. Torres Cacoullos 1999a; 1999b; 2000; 2001;Villalpando-Quiñonez s.a.). A continuación, resumimos las pocas observaciones que se hacen en la bibliografía sobre el uso de la perífrasis en dicha variedad dialectal ${ }^{3}$.

$\mathrm{Al}$ discutir las clases de verbos con los que andar puede formar perífrasis, la RAE y ASALE (2009: 2201) señalan que en México, así como en varios otros países americanos, se usa andar + GER con el verbo faltar para expresar la carencia reiterada de algo. Barajan la hipótesis de que estas ocurrencias estén influidas por el portugués de Brasil, donde son frecuentes. Asimismo, Cotton y Sharp (1988: 156) mencionan que el sistema verbal mexicano tiende a ser más analítico, en el sentido de que está más inclinado a expresar una idea con una perífrasis, que a veces consta de un verbo de movimiento, especialmente ir y andar. Además, basándose en una muestra de 24 ocurrencias obtenidas del habla culta de la Ciudad de México, Luna Trail (1980: 205-206) caracteriza andar + GER como una perífrasis durativa neutra, al igual que estar + GER, si bien la última es mucho más frecuente. Según la autora, los 24 ejemplos expresan una idea de inquieta actividad y transmiten desasosiego, solicitud o indeterminación (1980: 206). Por otra parte, Torres Cacoullos (2001) analiza el uso de andar + GER en varios corpus mexicanos y encuentra, entre otras cosas, que el uso de la perífrasis de andar es cuatro veces más frecuente en el habla popular que en el habla culta de la Ciudad de México.

En el presente trabajo nos proponemos analizar el uso de la perífrasis con andar en el español mexicano, ya que este dialecto parece ser especialmente receptivo a su empleo, pero hasta la fecha, hasta donde sabemos, no se ha estudiado en detalle. Específicamente, nos interesa el proceso de gramaticalización al que ha estado sometido andar + GER, tal como se discute en varios estudios sobre esta perífrasis (Alonso 1951; Camus Bergareche 2004; García Padrón 1990; Squartini 1998; Torres Cacoullos 1999b; 2000;

\footnotetext{
Somos conscientes de que las zonas dialectales americanas no siempre coinciden con los territorios nacionales de los distintos países americanos. Sin embargo, por comodidad nos referimos con el término de dialecto o variedad dialectal al habla específica de un país.
} 
2001; 2012; Villalpando-Quiñonez s.a.), así como también el grado de gramaticalización de la perífrasis en el español mexicano actual. Para tal fin, haremos un análisis diacrónico y sincrónico centrándonos tanto en características semánticas como formales.

En la sección 2 discutiremos la frecuencia histórica de la perífrasis. Para ello, consultaremos distintos corpus diacrónicos y sincrónicos, que se describen brevemente en la misma sección. En la medida de lo posible contrastaremos los datos encontrados para el español de México con los de otros dialectos del español y con los del español peninsular en particular. La sección 3 trata el valor semántico de la perífrasis, además de las posibilidades combinatorias de andar + GER, también desde una perspectiva tanto diacrónica como sincrónica. En la sección 4 ofrecemos un análisis sintáctico diacrónico de la perífrasis al discutir cuatro propiedades estructurales que suelen relacionarse con procesos de gramaticalización. Finalmente, en la sección 5 se cierra el trabajo con un resumen de los resultados y las conclusiones más importantes.

\section{ACERCA DEL USO DE $A N D A R+$ GERUNDIO}

Hopper y Traugott (2003: 129-130) consideran el aumento de la frecuencia relativa de una forma o construcción a lo largo del tiempo un indicio del proceso de gramaticalización que está experimentando la misma, aduciendo que "the more frequently a form occurs in texts, the more grammatical it is assumed to be" (cf. también Bybee 2003). Hilpert (2012: 461-462) reconoce la relación entre frecuencia y gramaticalización, pero advierte que no está resuelta la cuestión de si un aumento en la frecuencia de una forma constituye la causa, la consecuencia o un efecto secundario del proceso de gramaticalización (cf. también Traugott 2010: 282; Mair 2011: 242-243).

No obstante la falta de acuerdo y claridad sobre el papel exacto de la frecuencia relativa de una forma en los procesos de gramaticalización, conviene indagar si en perspectiva diacrónica y diatópica se detectan cambios o diferencias entre el español de México, por un lado, y otros dialectos, por otro lado. Tal comparación nos permite valorar debidamente los datos encontrados para el español mexicano y determinar hasta qué grado el empleo de la perífrasis en México es único o difiere del uso de la perífrasis en otras variedades del español. Nuestras observaciones estarán basadas en datos reales de distintos corpus que pasamos a describir en el siguiente apartado. 


\subsection{CORPus}

Para el presente estudio utilizamos cuatro corpus distintos, dos de ellos diacrónicos y dos sincrónicos. El corpus diacrónico GRADIA, compilado por el grupo de investigación del mismo nombre, abarca el periodo cronológico que se extiende desde el siglo IX hasta el siglo XxI y comprende distintos géneros textuales, con un total de 490 documentos. De las ediciones textuales incorporadas la fecha de creación del texto original y la fecha del manuscrito en que se ha conservado el mismo, no superaran los treinta años, hecho evidentemente esencial en todo estudio lingüístico diacrónico (véase para más detalles http://Gradiadiacronia.wixsite.com/Gradia/corpus-Gradia). La mayor parte de los textos es de procedencia peninsular, pero el corpus también recoge una pequeña selección de textos de origen mexicano.

Además, para obtener datos diacrónicos adicionales, consultamos el corpus del Nuevo Diccionario Histórico del Español (CDH) creado por la Real Academia Española, concretamente el subcorpus de textos enmarcados entre el siglo XII y 1975, que constituye una selección de obras procedentes del CORDE (véase http://www.rae.es/recursos/banco-de-datos/cdh). Si bien este último presenta serios problemas de datación de un considerable número de textos medievales, al corresponder la fecha dada por CORDE con la fecha del texto original y no con la fecha de la copia reproducida (cf. Rodríguez Molina y Octavio de Toledo y Huerta 2017), para remediar ese problema en CDH se ha procedido a indicar la fecha del testimonio base junto a la fecha de creación del texto medieval si ambas no coinciden (http://web.frl.es/ CNDHE/org/publico/pages/ayuda/ayuda.view). De esta manera, se salva el investigador de posibles periodizaciones erróneas o dataciones incorrectas.

Para el periodo actual manejamos dos corpus distintos: el Corpus del Español Mexicano Contemporáneo (CEMC) y el Corpus del Español: Web/ Dialectos (CdE/Web). El primero comprende tanto textos escritos como transcripciones de conversaciones grabadas, agrupados en distintos géneros y pertenecientes a distintos niveles del habla (véase http://www.corpus. unam.mx:8080/cemc/). El segundo corpus, recopilado por Mark Davies, contiene dos mil millones de palabras que fueron extraídas de páginas web de 21 países de habla hispana (véase https://www.corpusdelespanol.org/ web-dial/).

Como veremos, estos cuatro corpus juntos nos proporcionarán amplios datos diacrónicos y contemporáneos de andar + GER, y, al mismo tiempo, nos brindarán la oportunidad de distinguir entre variedades dialectales. 


\subsection{FReCuenCia RELATIVA DE LA PERÍfRasis}

EN MÉXICO Y ESPAÑA: PERSPECTIVA DIACRÓNICA

Si bien la contribución de textos mexicanos al corpus GRADIA es modesta, con 47 textos, como primer paso examinaremos la frecuencia relativa de la perífrasis en este corpus, en textos tanto de origen mexicano como de origen peninsular a partir del siglo XVI, ya que es en ese siglo cuando se producen los primeros documentos en la zona que en la actualidad corresponde al territorio mexicano. A tal efecto, hemos extraído todos los casos de andar + GER en los que la forma verbal de andar y el gerundio están en adyacencia, es decir, no separados por ningún otro constituyente o palabra, como es el caso en los ejemplos (1) y (2). La Tabla 1 arroja los resultados. En ella, se expresa la frecuencia de la construcción por millón de palabras, puesto que el número de textos, al igual que el número de palabras por texto, varía considerablemente según el dialecto.

\begin{tabular}{|l|r|r|r|}
\hline dialecto & palabras & casos & frecuencia por millón \\
\hline mexicano & 636.073 & 85 & 133,63 \\
\hline peninsular & 18.736 .716 & 610 & 32,56 \\
\hline
\end{tabular}

Tabla 1: Frecuencia de andar + GER adyacentes en textos mexicanos y peninsulares (GRADIA)

Los datos de la Tabla 1 no dejan lugar a duda de que existe una diferencia diatópica entre el uso de la perífrasis con andar en el español mexicano frente al español peninsular. En el primer dialecto la misma es cuatro veces más frecuente que en el segundo dialecto, una diferencia que resulta estadísticamente significativa ${ }^{4}$.

Los textos mexicanos del corpus GRADIA no documentan andar + GER en todos los siglos sino solo en los siglos XVI, XVII y XX. Por eso, un análisis diacrónico de la perífrasis a partir de este corpus, necesariamente, solo puede darnos una vista parcial. Sin embargo, a raíz de la clara diferencia entre el empleo de andar + GER en México y en España, se plantea la cuestión de si dicha diferencia es un fenómeno reciente o si se remonta ya a épocas anteriores. Para contestar a esta pregunta, presentamos la frecuencia de la perífrasis por siglo y por dialecto en la Tabla 2.

4 Con $\mathrm{p}<0,01$ (valor prueba $\mathrm{Z}=13,2362, \mathrm{p}<0,00001$ ). 


\begin{tabular}{|l|l|r|r|r|}
\hline siglo & dialecto & palabras & casos & frecuencia por millón \\
\hline \multirow{3}{*}{ XVI } & mexicano & 74.192 & 7 & 94,35 \\
\cline { 2 - 5 } & peninsular & 3.760 .895 & 184 & 48,92 \\
\hline \multirow{3}{*}{ XVII } & mexicano & 11.928 & 1 & 83,84 \\
\cline { 2 - 6 } & peninsular & 2.356 .960 & 121 & 51,34 \\
\hline \multirow{3}{*}{ XX } & mexicano & 549.953 & 77 & 140,01 \\
\cline { 2 - 6 } & peninsular & 1.545 .485 & 41 & 26,53 \\
\hline \multirow{3}{*}{ total } & mexicano & 636.073 & 85 & 133,63 \\
\cline { 2 - 6 } & peninsular & 18.736 .716 & 610 & 32,56 \\
\hline
\end{tabular}

Tabla 2: Frecuencia de andar + GER adyacentes en textos mexicanos y peninsulares por siglo (GRADIA)

Como se puede ver, en los siglos en los que se documenta la perífrasis en los textos mexicanos, la frecuencia relativa para cada siglo es más alta que en el español de España para el correspondiente siglo. Si la diferencia ya es considerable en los siglos XVI y XVII, en el siglo XX es francamente notable ${ }^{5}$.

En vista de la falta de textos mexicanos dieciochescos y decimonónicos utilizamos el CDH para completar el panorama diacrónico. Si bien los textos más antiguos de este corpus datan del siglo XII, hemos limitado la extracción de datos al periodo 1520-1973, lo que corresponde respectivamente con las fechas del texto mexicano más antiguo y más reciente en el $\mathrm{CDH}^{6}$. La Tabla 3 despliega los resultados.

5 La diferencia entre el español mexicano y el peninsular solo tiene significación estadística con $\mathrm{p}<0,01$ para el siglo $\mathrm{xx}$ (valor prueba $\mathrm{Z}=9,6316, \mathrm{p}<0,00001$ ). Para los demás siglos, las diferencias no llegan a ser significativas con $\mathrm{p}<0,05$. Por otra parte, somos conscientes de que, a raíz de las Tablas 2 y 3 , no es adecuado calificar las diferencias de uso observadas en el siglo XVI simplemente como diferencias dialectales, ya que nos encontramos en el periodo inicial de la formación del español de México, época en la que es probable que el habla todavía fuera adquiriendo sus rasgos específicos que más tarde caracterizarían este dialecto.

${ }^{6}$ Hemos verificado que para todos los textos de los que fueron extraídos los ejemplos, la fecha de creación y la fecha del testimonio base coinciden (indicado por el CDH si no es el caso; véase el apartado 2.1.). Por otra parte, dado que el terminus post quem del periodo de estudio corresponde a 1520, no esperábamos mayores discrepancias de datación; cf. Rodríguez 


\begin{tabular}{|l|l|r|r|r|}
\hline siglo & dialecto & palabras & casos & frecuencia por millón \\
\hline \multirow{3}{*}{ XVI } & mexicano & 1.381 .140 & 184 & 133,22 \\
\cline { 2 - 5 } & peninsular & 41.331 .735 & 1942 & 46,99 \\
\hline \multirow{3}{*}{ XVII } & mexicano & 1.788 .228 & 70 & 39,14 \\
\cline { 2 - 6 } & peninsular & 29.440 .586 & 1153 & 39,16 \\
\hline \multirow{3}{*}{ XVIII } & mexicano & 702.319 & 6 & 17,94 \\
\cline { 2 - 6 } & peninsular & 8.472 .531 & 152 & 17,14 \\
\hline \multirow{3}{*}{ XIX } & mexicano & 1.050 .338 & 18 & 11,36 \\
\cline { 2 - 6 } & peninsular & 36.629 .335 & 416 & \\
\hline \multirow{3}{*}{ XX } & & & & \\
\hline & mexicano & 1.114 .623 & 76 & 13,93 \\
\hline & peninsular & 45.010 .783 & 627 & 26,67 \\
\hline & & & & \\
\hline \multirow{2}{*}{ total } & mexicano & 6.036 .648 & 354 & \\
\cline { 2 - 6 } & peninsular & 160.884 .970 & 4290 & \\
\hline
\end{tabular}

Tabla 3: Frecuencia de andar + GER adyacentes en textos mexicanos y peninsulares por siglo $(\mathrm{CDH})$

La Tabla 3 confirma, a grandes rasgos, el panorama general ya observado en el corpus GRADIA: la perífrasis es más frecuente en textos mexicanos que en textos peninsulares, en la mayor parte del período analizado, salvo en el siglo XVII, cuando las frecuencias para el español mexicano y peninsular son iguales y en el siglo XVIII, cuando el empleo de andar + GER en el español de España es dos veces más que en el español de México ${ }^{7}$.

Molina y Octavio de Toledo y Huerta (2017), que se centran en textos medievales anteriores a 1492, el periodo claramente más problemático para la datación de textos.

7 Es posible que el predomino de la perífrasis en el español peninsular frente al mexicano del siglo XVIII se deba a la composición del corpus $\mathrm{CDH}$ en ese siglo. Es verdad que la contribución al corpus de textos mexicanos frente a textos peninsulares en épocas anteriores al siglo XIX es relativamente pequeña, por lo cual quizá no representen bien la realidad lingüística (cf. http://web.frl.es/CNDHE/org/publico/pages/ayuda/ayuda.view). Sin embargo, las diferencias observadas para los siglos XVII y XVIII no son significativas (con $p<0,05$ ), como tampoco lo es para el siglo XIX. Para el siglo XVI y XX si hay significación estadística con $\mathrm{p}<$ 
Además, es interesante comprobar que en los siglos XVI y XVII la frecuencia relativa de la perífrasis en el español peninsular es la más alta, y que luego disminuye sin volver a recuperar el terreno perdido, evolución que se observa también en los textos peninsulares de Gradia (cf. Nieuwenhuijsen en prensa 2019). Dicha decaída no se produce en el español mexicano, puesto que, si bien la frecuencia relativa disminuye a partir del siglo XVII, en el siglo XIX $\mathrm{y}$, sobre todo, en el xx claramente vuelve a aumentar ${ }^{8}$.

\subsection{Frecuencia Relativa de la PeríFrasis EN MÉXICO Y ESPAÑA: PANORAMA SINCRÓNICO}

De los datos presentados hasta ahora se desprende que, por una parte, el empleo de la perífrasis, en general, parece ser más frecuente en México que en España y que, por otra parte, en México su uso parecer haberse disparado en épocas recientes. Dichas conclusiones invitan a plantearnos hasta qué grado el panorama descrito es típico del español mexicano y no de otros dialectos americanos o del español americano en general. Para contestar a esa pregunta aprovechamos el CdE/Web, que recoge el lenguaje contemporáneo en la red de distintos países americanos y, por ello, facilita hacer una comparación entre distintos dialectos.

La Tabla 4 resume las frecuencias de andar + GER en los siete países de habla hispana cuyo volumen de palabras en el corpus es de más de 100 millones.

\begin{tabular}{|l|r|r|r|}
\hline país & palabras & casos & frecuencia por millón \\
\hline México & 260.598 .272 & 6443 & 24,72 \\
\hline Argentina & 182.704 .898 & 3771 & 20,64 \\
\hline Venezuela & 107.978 .889 & 2006 & 18,58 \\
\hline
\end{tabular}

0,01 (valor prueba $Z=4,1314$ y 14,4938 respectivamente, con $\mathrm{p}<0,00001$ para ambos siglos). Por otra parte, es de notar que el Corpus Diacrónico y Diatópico del Español de América (Cordiam) (véase http://www.cordiam.org/) presenta también la frecuencia relativa más baja en el siglo XVIII (véase la nota 8).

8 Las dos tendencias, es decir la baja frecuencia de la perífrasis en el español mexicano del siglo XVIII y el aumento del empleo en épocas más recientes son corroboradas por el Corpus Diacrónico y Diatópico del Español de América (Cordiam) (véase http://www.cordiam.org/). En este corpus, la frecuencia por millón de palabras y por siglo es: siglo XVI 96,94; siglo XVII 83,28; siglo XVIII 19,30; siglo XIX 33,22. Cordiam no contiene textos del siglo XX. 


\begin{tabular}{|l|c|c|c|}
\hline Estados Unidos & 179.928 .189 & 3063 & 17,02 \\
\hline Perú & 115.324 .436 & 1941 & 16,83 \\
\hline Colombia & 180.145 .658 & 2294 & 12,73 \\
\hline España & 459.312 .821 & 6474 & 14,09 \\
\hline
\end{tabular}

Tabla 4: Frecuencia de andar + GER adyacentes en páginas web en distintos países de habla hispana (CdE/Web)

En primer lugar, los datos de la Tabla 4 corroboran la diferencia de uso de la perífrasis en el español de México frente al español de España, si bien la diferencia no es tan marcada como en los corpus analizados antes ${ }^{9}$. En segundo lugar, la Tabla 4 muestra claramente que el uso relativamente alto no es un fenómeno americano general, ya que se observan diferencias notables en la frecuencia relativa de andar + GER en los distintos países. Mientras que México despliega la frecuencia relativa más alta de todos, en Argentina también es relativamente frecuente el uso, aunque no llega a tener la misma frecuencia relativa que en México ${ }^{10}$. En Colombia, en cambio, el empleo de la perífrasis es el más bajo de todos siendo incluso más bajo que en España ${ }^{11}$.

\subsection{VARIACIÓN, MODALIDAD DEL HABLA Y GÉNERO TEXTUAL}

En el corpus Gradia, el uso de la perífrasis en el español mexicano es particularmente alto en el siglo xx. Como todos los casos de este siglo corresponden al lenguaje oral, mientras que el corpus para el español mexicano también recoge otros géneros textuales (discurso político, epistolario, textos legales y prensa), se podría suponer que existe una correlación entre el uso de la perífrasis y la modalidad (lengua escrita -

9 La diferencia es significativa con $\mathrm{p}<0,01$ (valor prueba $\mathrm{Z}=32,3558, \mathrm{p}<0,00001$ ).

10 Aunque pequeña, la diferencia entre México y Argentina sí tiene significación estadística con $\mathrm{p}<0,01$ (valor prueba $\mathrm{Z}=8,8177, \mathrm{p}<0,00001$ ).

11 Es interesante contrastar nuestros resultados con los de Sedano (2000). Esta autora compara el empleo de varias perífrasis de gerundio, entre ellas andar + GER, en el habla de Caracas con el registrado en Bogotá, la Ciudad de México, La Habana y Madrid por otros autores. En sus datos el empleo de andar es sumamente reducido, lo cual, según ella, "permite confirmar su desuso como auxiliar en el español hablado actual". Pese a que el presente trabajo traza un panorama completamente diferente, mucho más optimista, llama la atención que entre los escasos usos de andar + GER registrados por Sedano los de la Ciudad de México también sean los más frecuentes de todos. 
lengua hablada) ${ }^{12}$. Dado que en el CEMC se puede distinguir entre géneros escritos y conversaciones grabadas, es posible comprobar si, de hecho, existe una diferencia de uso según la modalidad del habla. En la Tabla 5 se ofrece la frecuencia de la perífrasis en textos escritos frente al lenguaje oral ${ }^{13}$.

\begin{tabular}{|l|r|r|r|}
\hline & palabras & casos & frecuencia por millón \\
\hline escrito & 1.707 .544 & 158 & 92,53 \\
\hline oral & 183.501 & 115 & 626,70 \\
\hline
\end{tabular}

Tabla 5: Frecuencia de andar + GER adyacentes en textos escritos y lenguaje oral mexicanos (CEMC)

Los resultados de la Tabla 5 ponen en evidencia que la perífrasis de andar es más frecuente en la modalidad hablada que en la escrita. Concretamente, en el CEMC andar + GER ocurre más de seis veces más en el habla oral que en los textos escritos, siendo la diferencia significativa ${ }^{14}$. Estos datos, por lo tanto, corroboran la hipótesis de que la modalidad influye en el uso de la perífrasis, y que es la modalidad oral la que favorece más el empleo de andar $+\mathrm{GER}^{15}$.

El CdE/Web ofrece la posibilidad de distinguir entre páginas web generales y blogs. Los blogs exhiben un registro informal, que se acerca a la lengua hablada y que se caracteriza por la inmediatez comunicativa (cf. Koch y Oesterreicher 1990: 5-6; Oesterreicher 1996: 317-20). Sindoni (2013: 38-40) afirma que la interacción en línea suele ser más amigable, abierta e informal y que, a pesar de que mucha comunicación mediada por ordenador es escrita, normalmente se asocia más con el habla oral, ya que ambas son

12 Cf. Camus Bergareche (2004: 556) que sostiene que la diferencia entre andar + GER y estar + GER en muchos casos es meramente estilística, siendo la perífrasis más marcada y más enfática.

13 Si bien lo permite el corpus, no distinguimos, dentro de la modalidad oral, entre lengua culta, sub-culta y no estándar, ya que el total de los casos de andar + GER en lenguaje oral no es lo suficientemente alto para poder atomizar más. Por otra parte, como ya comentábamos, Torres Cacoullos (2001) encontró que la perífrasis con andar era mucho más frecuente en el habla popular que en el habla culta de la Ciudad de México.

14 Con $\mathrm{p}<0,01$; valor prueba $\mathrm{Z}=18,1648, \mathrm{p}<0,00001)$.

15 Se observa la misma tendencia, aunque mucho menos destacada, en el Corpus del Español del Siglo XXI (CORPES XXI). En el subcorpus del español de México, distinguiendo entre medio escrito y oral, la frecuencia de la perífrasis por millón de palabras en el periodo 2002-2016 es de 25,16 en la lengua escrita (932 casos) frente a 32,63 en la lengua hablada (5 casos). 
efímeras y no permanentes. Según la autora, el uso de lenguaje informal, tal como aparece en interacciones en la red como blogs personales, chats en vídeo o comunidades de redes sociales, concuerda con la preferencia por un lenguaje rápido no revisado, al emplear rasgos del habla oral en vez de formas más refinadas y pulidas, que son características de la escritura tradicional y formal.

Añade Lomborg (2009) que la informalidad de los blogs se puede atribuir, según algunos autores, a la borrosidad entre textualidad y oralidad, típica de varios géneros de comunicación mediada por ordenador.

La Tabla 4 contenía datos para el total de las páginas web por país incorporadas en el corpus CdE/Web. Si nos fijamos en los blogs, se nos presenta el siguiente panorama (Tabla 6).

\begin{tabular}{|l|r|r|r|}
\hline país & palabras & casos & frecuencia por millón \\
\hline México & 127.946 .347 & 4062 & 31,75 \\
\hline Argentina & 89.509 .348 & 2229 & 24,90 \\
\hline Venezuela & 66.306 .730 & 1443 & 21,76 \\
\hline Perú & 68.204 .165 & 1255 & 18,40 \\
\hline Estados Unidos & 85.324 .555 & 1493 & 17,50 \\
\hline Colombia & 95.859 .929 & 1370 & 14,29 \\
\hline España & 250.504 .154 & 3915 & 15,63 \\
\hline
\end{tabular}

Tabla 6: Frecuencia de andar + GER adyacentes en blogs en distintos países de habla hispana (CdE/Web)

Si se comparan los datos para blogs (Tabla 6) con los de las páginas web en general (Tabla 4), se hace evidente que el uso de andar + GER es particularmente frecuente en blogs, es decir, en un género textual relativamente informal que comparte características con la lengua hablada. En todos los países analizados la perífrasis aparece con una frecuencia relativa más alta en blogs que en páginas web en general. La mayor diferencia se observa en el español de México, la menor en el de Estados Unidos. Podemos concluir, por lo tanto, que, además de que el uso de la perífrasis es típico del español mexicano, su uso destaca, sobre todo, en contextos de lengua o géneros pertenecientes a registros informales, sea el habla oral, sean textos escritos "inmediatos" como los blogs. 


\section{ACERCA DEL VALOR SEMÁNTICO DE $<A N D A R+$ GERUNDIO $>$}

En esta sección nos centramos en los rasgos semánticos de la perífrasis con andar, tanto desde una perspectiva cualitativa, al comentar el significado de unos ejemplos en concreto, como desde una perspectiva cuantitativa, al discutir las distintas clases de verbos que puede seleccionar el auxiliar andar para formar perífrasis de gerundio.

\subsection{ANÁlisis CUALITATIVO: DE MOVIMIENTO FÍSICO A MATICES DE DETERMINACIÓN Y EMPEÑO}

Como ya se ha mencionado antes, las primeras ocurrencias de la perífrasis en textos de origen mexicano datan del siglo Xvi. Estas, en parte, presentan la perífrasis como la combinación de un verbo de movimiento físico, generalmente sin dirección fija (andar), y un gerundio que expresa una segunda acción, simultánea a la primera. Ya en latín el verbo del que procede andar, AMBULĀRE ('andar por ahí', 'deambular') recogía el matiz de movimiento indeciso, sin rumbo fijo ${ }^{16}$. Este tipo de ejemplos correspondería a los que Cuervo (1994 [1886]: 459) caracteriza como "conservando uno y otro verbo su valor natural, de modo que se representan distintamente dos acciones". En (3) y (4) se ejemplifica este tipo de casos.

(3) (...) de que no tengo dubda, porque un religioso, padre guardian, que andava predicando los jndios por aquellas provjncias, me dixo y certeficó que él mesmo encontro al hermano de Delgadillo. (Fray Juan de Zumárraga, Documentos lingüisticos de la Nueva España, 1529, Gradia)

(4) (...) y solían andar con unas petaquillas o a cuestas, y entre las casas andar vendiendo las yervas medicinales que llaman patli. (Fray Bernardino de Sahagún, Historia general de las cosas de Nueva España, 1576, СDH)

16 Según la RAE y ASALE (2009: 2107, 2199) en latín AMBULĀRE ya era un verbo frecuentativo, lo que explicaría por qué andar se combina muy a menudo con verbos frecuentativos como callejear, husmear, etcétera (RAE y ASALE 2009: 2107). No obstante, no creemos que AMBULĀRE fuera frecuentativo en latín (cf. Glare 1968: 116, s.v. AMBULŌ), ni tampoco que andar lo sea en español, como explicaremos a continuación. 
En (3), se trata de un religioso que se desplaza físicamente, al mismo tiempo que realiza otra acción, la de predicar. El complemento adverbial de lugar, por aquellas provjncias, refuerza la idea de movimiento físico, así como la de falta de dirección fija. El ejemplo (4) relata que un grupo de indígenas, grandes conocedores de plantas y raíces, venden plantas medicinales por la calle. Esto implica un movimiento físico (el de andar por las calles) y simultáneamente involucra una segunda acción, la de vender.

No obstante, ya en el siglo XVI nos encontramos con casos en que el verbo andar no necesariamente o no únicamente expresa un movimiento físico, por lo cual la perífrasis puede adquirir una interpretación más pragmática, que viene dada por el contexto específico. Compárense los ejemplos (5) y (6).

(5) Los procuradores de los pueblos, por escusar alborotos y escandalos, viendo lo que avia hecho Rrodrigo de Paz, y otro alboroto que asy mjsmo andovo levantando Francisco de las Casas, y que tanbjen se sonavan no mejores nuevas de Pedro de Alvarado que estava en Guatymala. (Diego de Ocaña, Documentos lingüísticos de la Nueva España, 1526, GRADIA)

(6) (...) y sin decir nada a nadie se metieron por la tierra adentro más de cincuenta leguas, a convertir y enseñar otros Indios; y allá anduvieron padeciendo hartos trabajos e hicieron mucho fruto. (Fray Toribio de Benavente, Historia de los Indios de la Nueva España, 1536, CDH)

En la carta de la que proviene el ejemplo (5), el escritor se refiere a Francisco de las Casas, que aparentemente está causando un alboroto. Antes del fragmento reproducido en (5) el escritor ya ha comentado que un grupo de gente, con hombres armados entre ellos, va a juntarse con ese Francisco de las Casas que llegava de las Higueras y estava veynte leguas de aquj, para que entrase con vara y qujtase la juridiçion a los dichos fator $y$ veedor. A pesar de que la acción expresada por el predicado de la perífrasis, así como la descripción anterior del sujeto de andar + GER, conlleva un movimiento físico, se infiere también que la actividad realizada por Francisco de las Casas tiene cierta duración y progresión, e implica un tipo de determinación por parte del sujeto. En (6), el significado del predicado padecer no exige desplazamiento o movimiento físico, si bien no está excluido del todo. En cambio, además de hacer hincapié en la duración y la progresión de la situación, andar + GER transmite un sentido de tenacidad e intensidad, inferido por el contexto inmediato de sin decir nada a nadie y se metieron por la tierra adentro más de cincuenta leguas. Es probable que precisamente por este tipo de ejemplos ambiguos varios autores le atribuyan a la perífrasis valores de ocupación (Keniston 1937: 469), preocupación (García González 
1992: 54; Keniston 1937: 469), ansiedad (Cuervo 1994 [1886]: 460; Keniston 1936: 172) o esfuerzo (Garcés Gómez 1992: 439).

A nuestro modo de ver, lo que tienen estos ejemplos en común no es tanto un valor de iteratividad o frecuentatividad (entendido como la realización de una situación o acción en varias ocasiones o muchas veces; cf. Dik 1997: 236), que suelen atribuirle muchos autores (véase la introducción), sino más bien un sentido de duración progresiva (entendido como una situación o acción en curso; cf. Dik 1997: 223), que está realizándose poco a poco pero con intensidad, y que conlleva cierta determinación o empeño por parte del agente que la provoca o la ejecuta ${ }^{17}$. Por otra parte, la situación o acción en curso hasta cierto grado está segmentada, estando los segmentos interrelacionados el uno con el otro. De hecho, según Camus Bergareche (2004: 554) si la perífrasis selecciona verbos que corresponden a realizaciones y logros, se interpretan estos predicados como "actividades compuestas de varios subeventos télicos repetidos".

Entre los ejemplos del siglo xx se encuentran casos tan 'dispares' como los de (7) a (10), en los que el significado del gerundio no es compatible en absoluto con la idea de movimiento físico y que transmiten distintos matices pragmáticos (cf. Heine 2003).

(7) Pues, en que... yo supe que nunca lo hacía, es decir, porque a tal hora estaba en el cine; porque a tal hora andaba cenando en casa de unos primos. “¡Ay! ¿Cómo lo hago?”, me decía. (Juan M. Lope Blanch (coord.), El habla de la ciudad de México, 1971, GradiA)

(8) Decía: “¡No! ¡Pus yo qué me voy a andar casando con ése! ¡Pus cómo me voy a casar! (Juan. M. Lope Blanch (coord.), El habla popular de la ciudad de México, 1976, GRADIA)

17 Camus Bergareche (2004: 553-556) argumenta que no se admite andar + GER en contextos de lectura gradual y télica sino únicamente ir + GER, mientras que en contextos habituales y atélicos solo es posible andar + GER. Por otra parte, según él solo estar + GER tiene una lectura verdaderamente progresiva en tanto que la de andar + GER es continua. Una discusión más profunda de los distintos valores de andar, ir y estar con gerundio queda fuera del marco del presente artículo, pero no nos parece del todo apropiado caracterizar andar + GER como continuativo, en tanto en cuanto entendido como ocurriendo continuamente sin interrupción o punto final (cf. Dik 1997: 223). En cambio, creemos que un aspecto fundamental de la perífrasis de andar es el de determinación y perseverancia. Dichos valores añadidos, obviamente, se relacionan conceptualmente con los matices de (pre)ocupación, ansiedad y esfuerzo aducidos por distintos autores. Para más discusiones acerca de la diferencia entre los distintos perífrasis de gerundio, véanse, por ejemplo, Hamplová 1968; Markič 2006; Sarrazin 2011. 
(9) He escuchado historias de terror de diseñadores freelanceros que, por andar quedando bien, se prestan a muy malos entendidos cuando aceptan visitar al cliente en su departamento, en sábado, a las 8 de la noche. (http://clientesmalos.com/, CdE/Web)

(10) Kreo k esta de mas decir k la cancion esta padrisima, esta si es musika no como otras canciones k andan sonando por ahi!!!! (http://www. ideasnopalabras.com/2007/11/mariah-carey-without-you-traducidocastellano/, CdE/Web)

En (7) el sujeto de la perífrasis no logra pensar en otra persona (el hablante) a una determinada hora durante cinco minutos, es decir no está dispuesto a interrumpir sus actividades diarias para eso. Además de un valor durativo, de ocupación (Keniston 1937: 469), lo que se infiere en (7) es que el hablante le confiere al sujeto un tipo de determinación y de intención. En (8) la perífrasis andar + GER forma parte de una cadena perifrástica (me voy a andar casando), de la que se repite la primera en la segunda parte de la enunciación (me voy a casar). La mujer, que se refiere a sí misma en este enunciado, niega que tenga la intención o esté determinada a casarse con cierto hombre. El valor que transmite esta perífrasis, por lo tanto, aplicando los matices que se describen en los distintos estudios, sería el de énfasis (Yllera 1999: 3417), desasosiego (Luna Trail 1980: 206) o ansiedad (Cuervo 1994 [1886]: 460; Keniston 1936: 172). Estos matices se deducen, en gran parte, del contexto, particularmente del tono exclamativo, reflejado en los signos de exclamación, y del léxico (No; qué ...; con ése ; cómo ...).

Por otra parte, en (9) el gerundio es un verbo de estado (quedar), cuyo perfil semántico no es muy compatible con el de andar ${ }^{18}$. Sin embargo, también en este caso se infiere un sentido de determinación o intención por parte de los diseñadores freelanceros, quienes por conseguir un encargo, otorgan todo tipo de peticiones para complacer al cliente.

Finalmente, el sujeto de (10) es inanimado e indefinido (otras canciones), lo cual es totalmente incompatible con el significado léxico de andar de

18 Existen opiniones ligeramente divergentes acerca de la capacidad de la perífrasis de combinarse con predicados estativos. Según García Fernández (2006: 88), la perífrasis es compatible con estados no permanentes, la que en tal caso adquiere una interpretación dinámica. Olbertz (1998: 470) sostiene que andar + GER no puede aparecer en estados de cosas no dinámicos. Squartini (1998: 262) sí menciona la posibilidad de que andar ocurra con verbos de estado y presenta ejemplos con preocupar y querer. Camus Bergareche (2004: 554) también afirma que algunos estados admiten la perífrasis y cita ejemplos con querer, tener y ser. 
'moverse el animal por sus pies de un lugar a otro' (Covarrubias Horozco 1611) o de 'ir de un lugar a otro dando pasos' (RAE y ASALE 2015, $1^{\text {a }}$ acepción). Olbertz (1998: 469-470) sostiene que la selección del sujeto de la perífrasis queda restringida por el rasgo de animicidad, lo cual se debe a que la acción de andar requiere una entidad capaz de moverse de manera autónoma. Según ella, el uso de sujetos inanimados, que pueden aparecer bajo ciertas circunstancias, está marcado y no es muy general, observación corroborada por nuestro corpus, en el que los casos de sujetos inanimados también son escasos. Excluida la inferencia de empeño por parte del sujeto de la perífrasis, en (10) se transmite más bien la idea de duración persistente y también un matiz despectivo de desprecio (cf. Fente, Fernández y Feijóo 1972: 34; García González 1992: 54; Hamplová 1968: 222; Llorente Vigil 1999: 56; Yllera 1999: 3417).

Al surgir nuevos valores o matices como los que acabamos de observar en los ejemplos (5) a (10) estamos claramente ante una extensión semántica de la perífrasis andar + GER, más concretamente ante un cambio construccional, que siguiendo a Traugott and Trousdale (2013: 26) se puede definir como "a change affecting one internal dimension of a construction. It does not involve the creation of a new node." (cf. también Traugott 2015) ${ }^{19}$.

En el siguiente apartado profundizaremos más en el cambio semántico de andar + GER analizando con qué clases de verbos se junta andar para formar perífrasis.

\subsection{ANÁlisis CUANTITATIVO: SUBClASES DE VERBos - PANORAMA GENERAL}

Además del análisis e interpretación de ejemplos concretos, podemos medir la extensión semántica de andar + GER a través de las posibilidades combinatorias que exhibe. Según varios autores, la perífrasis manifiesta una preferencia por los predicados durativos atélicos, por actividades, debido a que el verbo andar es un verbo de movimiento sin orientación fija (Camus Bergareche 2004: 553; García Fernández 2006: 87; Squartini 1998: 256, 261; Torres Cacoullos 2001).

Nieuwenhuijsen (en prensa 2019) muestra que en el español peninsular actual andar selecciona, sobre todo, verbos de desplazamiento para formar perífrasis, seguido por verbos de comunicación. A continuación

19 La idea de node, 'nodo' supone que la lengua constituye una red de nodos con enlaces entre sí (cf. Traugott and Trousdale 2013: 3). 
examinaremos si la perífrasis muestra un comportamiento idéntico o similar en el español mexicano. Para clasificar los gerundios que aparecen en nuestro corpus de perífrasis, hemos consultado el banco de datos de verbos y construcciones verbales del español Adesse, en el que se ofrece una caracterización sintáctico-semántica de más de 4000 entradas verbales. Nos hemos centrado en las subclases distinguidas por Adesse, que pertenecen jerárquicamente al nivel más pormenorizado de la clasificación ${ }^{20}$.

En la Tabla 7 listamos en la columna izquierda todas las subclases de gerundios documentados con el verbo andar en el subcorpus mexicano Gradia ordenadas según el número total de ocurrencias ${ }^{21}$. A modo de comparación, ofrecemos en la columna derecha los mismos datos para el corpus peninsular. Cabe señalar que en este último corpus, como la perífrasis cuenta con muchas más ocurrencias en total, la variedad de subclases que se despliega es mucho mayor que en el corpus mexicano. Por motivos prácticos, hemos juntado todas las subclases del corpus peninsular que no se registran en el corpus mexicano en la categoría de 'otras" 22 .

20 En la clasificación de Adesse ciertos verbos se adscriben directamente a una clase y no a una subclase. En tales casos, el nivel jerárquicamente más bajo es la clase (en vez de la subclase). Este es el caso con los verbos de apoyo, los de comunicación y los de percepción de la Tabla 7. Por motivos de comodidad, en lo que sigue utilizaremos el término subclase para todas las clasificaciones, sabiendo que en algunos casos, de hecho, no se trata de una subclase sino de una clase.

${ }^{21}$ El corpus contiene ejemplos en los que el gerundio en cuestión, según la clasificación de Adesse, entraña una combinación de dos procesos, y por eso pertenece a dos subclases de verbos. Este es el caso, por ejemplo, con el verbo traducir del corpus peninsular, que semánticamente encierra un cambio y un acto de comunicación, y el verbo casar del corpus mexicano, que se clasifica como una combinación de relaciones sociales y de unión.

Puesto que estos verbos no se pueden adscribir a una sola subclase, se han excluido del presente cálculo ( 31 del corpus peninsular, 2 del corpus mexicano). Además, en el corpus peninsular buscar, de lejos, es el verbo más frecuente (13,8\%, 84 ocurrencias), por lo cual se puede argumentar que se trata de una locución fija (cf. Bybee y Torres Cacoullos 2009). Dada esta condición particular, es posible que los casos de $<$ andar buscando $>$ lleguen a influir de manera desproporcionada en los resultados, motivo por el cual los hemos excluido todos tanto del corpus peninsular como del mexicano. Es de notar que en el corpus mexicano buscar es el segundo verbo más frecuente $(9,4 \%$, ocho ocurrencias), detrás de hacer $(11,8 \%$, diez ocurrencias). Por último, el corpus peninsular contiene 36 ocurrencias del verbo discurrir, con el sentido de '[m]overse avanzando por un lugar' (RAE y ASALE 2015, 4a acepción). Corresponden al segundo verbo más frecuente, pero únicamente aparecen en dos textos historiográficos del siglo XVI. Para evitar que la particularidad de este verbo afecte los resultados desmesuradamente, hemos excluido también todas las ocurrencias de la perífrasis con este verbo. Nótese que el verbo discurrir no aparece en el corpus mexicano.

22 Falta espacio para poner ejemplos de todas las subclases mencionadas en la Tabla 7. Para la clasificación completa remitimos a la página web de Adesse. A modo de ilustración, la clase de verbos de comunicación incluye verbos como decir y preguntar; la subclase 


\begin{tabular}{|l|r|r|}
\hline subclase de verbo & mexicano & peninsular \\
\hline verbo de apoyo & $16 \%(12)$ & $3,1 \%(14)$ \\
\hline comunicación & $14,7 \%(11)$ & $9 \%(41)$ \\
\hline desplazamiento & $12 \%(9)$ & $20,4 \%(93)$ \\
\hline actividad & $8 \%(6)$ & $5,7 \%(26)$ \\
\hline modificación & $8 \%(6)$ & $5,3 \%(24)$ \\
\hline conocimiento & $6,7 \%(5)$ & $2,4 \%(11)$ \\
\hline percepción & $5,3 \%(4)$ & $8,6 \%(39)$ \\
\hline cambio de estado & $4 \%(3)$ & $0,4 \%(2)$ \\
\hline control & $4 \%(3)$ & $2,9 \%(13)$ \\
\hline adquisición & $2,7 \%(2)$ & $3,7 \%(17)$ \\
\hline contacto & $2,7 \%(2)$ & $0,9 \%(4)$ \\
\hline ingestión & $2,7 \%(2)$ & $1,3 \%(6)$ \\
\hline sensación & $2,7 \%(2)$ & $1,5 \%(7)$ \\
\hline cognición & $1,3 \%(1)$ & $0,9 \%(4)$ \\
\hline consumo & $1,3 \%(1)$ & - \\
\hline creación & $1,3 \%(1)$ & $2,6 \%(12)$ \\
\hline emisión de sonido & $1,3 \%(1)$ & $0,2 \%(1)$ \\
\hline localización & $1,3 \%(1)$ & $2,4 \%(11)$ \\
\hline petición & $1,3 \%(1)$ & $3,5 \%(16)$ \\
\hline transferencia & $1,3 \%(1)$ & $2 \%)$ \\
\hline
\end{tabular}

de verbos de desplazamiento recoge verbos como ir y pasear; en la subclase de verbos de actividad figuran verbos como jugar y trabajar; la subclase de modificación contiene arreglar y romper, entre otros. La categoría residual de 'otras' incluye 20 subclases de verbos. De ellas, las más grandes son las de competición (16 casos), con verbos como pelear, disposición (12 casos), con verbos como procurar, e inducción (10), con verbos como animar. Las demás subclases cuentan cada una con menos de 10 casos. Cabe señalar que en la clasificación de Adesse la clase de verbos de apoyo recoge dos tipos de grupos verbales. Por una parte, incluye los grupos verbales formados por un verbo, ligero o liviano, y un sustantivo abstracto que lo complementa. Este sería el caso de dar en dar voces y dar la vuelta. Por otra parte, comprende locuciones verbales, grupos de palabras lexicalizados y fijos como hacer caso (cf. RAE y ASALE 2009: 53 y ss.). En nuestro corpus la gran mayoría de las ocurrencias cabe en el grupo de los verbos de apoyo propiamente dichos. A efectos de presentación y a fin de evitar categorías muy fragmentarias hemos decidido no distinguir entre ambos grupos verbales en el presente cálculo. 


\begin{tabular}{|l|r|r|}
\hline uso & $1,3 \%(1)$ & $1,1 \%(5)$ \\
\hline otras & - & $22,1 \%(101)$ \\
\hline total & $100 \%(75)$ & $100 \%(456)$ \\
\hline
\end{tabular}

Tabla 7: Frecuencia relativa de subclases de verbos en andar + GER adyacentes en textos mexicanos y peninsulares (GRADIA)

Mientras que tanto en el español mexicano como en el peninsular andar + GER puede formar predicados con verbos semánticamente delexicalizados, como lo son los verbos de apoyo (RAE y ASALE 2009: 57), es el dialecto mexicano el que favorece dicha subclase de verbos sobre todas las demás subclases. Al mismo tiempo, en ambos dialectos la perífrasis selecciona verbos de desplazamiento, es decir, verbos semánticamente cercanos al significado léxico de andar, pero es solo en el español peninsular donde esta subclase de verbos predomina.

Los datos de la Tabla 7, por lo tanto, sugieren que en el español mexicano la perífrasis está sometida a menos restricciones combinatorias que en el español peninsular, o mejor dicho, los datos sugieren que la selección de los verbos semánticamente (semi)vacíos para formar perífrasis está más arraigada y normalizada en el español mexicano que en el español peninsular, lo que a su vez puede apuntar a un mayor grado de gramaticalización de andar + GER en el español de México.

\subsection{AnÁlisis CUANTITATIVO: SUbClases DE VERBOS - PERSPECTIVA DIACRÓNICA}

Para saber cuándo y cómo se extendieron, supuestamente, las posibilidades combinatorias de la perífrasis con andar en el español de México, no nos sirven los datos del subcorpus mexicano GRADIA, dado que antes del siglo xx solo documentamos ocho casos (cf. la Tabla 2). Por eso, para realizar tal análisis diacrónico de las subclases de verbos seleccionados por la perífrasis, utilizamos el $\mathrm{CDH}$, que presenta datos relativamente amplios para el español mexicano de los siglos XVI, XVII y XX, aunque hay que admitir que sus datos para los siglos XVIII y XIX también son escasos, motivo por el cual estos dos últimos siglos no están incorporados en el cálculo de la Tabla 8.

Para evitar demasiada atomización de los datos nos centramos en aquellas subclases de verbos que cuentan con una presencia de 10 ocurrencias o más en la totalidad del corpus de los siglos XVI, XVII y XX. Lógicamente, estas subclases, en su mayor parte, coinciden con las más frecuentes de la Tabla 7. 
La Tabla 8 ofrece los resultados por subclase, ordenados de mayor a menor número de ocurrencias ${ }^{23}$.

\begin{tabular}{|l|r|r|r|r|}
\hline & siglo XVI & siglo XVII & siglo Xx & total ocurrencias \\
\hline desplazamiento & $\begin{array}{r}33,9 \% \\
(41)\end{array}$ & $30 \%(12)$ & $18,2 \%(4)$ & 57 \\
\hline actividad & $\begin{array}{r}14,9 \% \\
(18)\end{array}$ & $15 \%(6)$ & $0 \%(0)$ & 24 \\
\hline percepción & $7,4 \%(9)$ & $15 \%(6)$ & $18,2 \%(4)$ & 19 \\
\hline verbo de apoyo & $6,6 \%(8)$ & $7,5 \%(3)$ & $27,3 \%(6)$ & 17 \\
\hline comunicación & $4,1 \%(5)$ & $10 \%(4)$ & $27,3 \%(6)$ & 15 \\
\hline ingestión & $9,9 \%(12)$ & $2,5 \%(1)$ & $9,1 \%(2)$ & 13 \\
\hline fisiología & $9,9 \%(12)$ & $2,5 \%(1)$ & $0 \%(0)$ & 12 \\
\hline control & $6,6 \%(8)$ & $10 \%(4)$ & $0 \%(0)$ & 11 \\
\hline transferencia & $6,6 \%(8)$ & $7,5 \%(3)$ & $0 \%(0)$ & 183 \\
\hline total & $\begin{array}{r}100 \% \\
(121)\end{array}$ & $100 \%(40)$ & $100 \%(22)$ & \\
\hline
\end{tabular}

Tabla 8: Frecuencia relativa de subclases de verbos en andar + GER adyacentes en textos mexicanos en los siglos XVI, XVII y xx (CDH)

Si se comparan los resultados para los tres siglos, se nota que los verbos de desplazamiento, que en los siglos XVI y XVII constituyen la subclase más seleccionada por la perífrasis (33,9\% y $30 \%$ respectivamente) y cuyo significado, en principio, es muy compatible con el significado léxico de andar, en el siglo xx claramente han perdido terreno (18,2\%). Por otra parte, hay tres subclases de verbos cuya frecuencia relativa aumenta a lo largo de los tres siglos, a saber los verbos de percepción, los verbos de apoyo y los

23 Al igual que en la Tabla 7, hemos excluido de este cálculo casos en los que el gerundio representa una combinación de dos procesos y, por ello, se categoriza en dos subclases diferentes (22 ocurrencias). Asimismo, hemos excluido los casos del verbo buscar por constituir, supuestamente, una locución fija con el verbo andar. Además, hemos excluido 19 casos de vacilar del siglo xx. Este verbo es el más frecuente en dicho siglo, por encima del verbo buscar, con cinco ocurrencias. Todas las ocurrencias de vacilar provienen de un mismo texto, lo que nos sugiere que estamos ante un uso muy idiosincrásico, típico del autor del texto, el jesuita Carlos María de Heredia. Vacilar tiene el significado de 'dudar al deber tomar una decisión', específicamente en relación con la fe. 
de comunicación. Es de notar que la frecuencia relativa de las últimas dos subclases se dispara sobre todo en el siglo xx. Las tendencias observadas a raíz de la Tabla 7, por lo tanto, se corroboran con los datos diacrónicos de la Tabla 8, en el sentido de que los verbos de apoyo y los de comunicación, los más frecuentes en el subcorpus mexicano GRADIA, van en aumento a lo largo de los siglos y llegan a predominar en el siglo xx. Además, los verbos de desplazamiento, que en el subcorpus mexicano Gradia constituyen la tercera subclase de verbos más seleccionados, diacrónicamente sufren una decaída considerable, siendo su frecuencia relativa en el siglo xx tres veces más baja que en el siglo XVI.

Los verbos de percepción presentan un panorama un tanto divergente, difícil de explicar. Mientras que en el subcorpus mexicano Gradia estos verbos no son seleccionados mucho por la perífrasis, los datos de la Tabla 8 indican que su uso aumenta a través del tiempo, por lo cual llega a ser la tercera subclase más frecuente en el siglo $\mathrm{xx}$, junto con los verbos de desplazamiento.

Como hemos comentado antes, se puede considerar la extensión semántica de andar + GER como un cambio construccional, puesto que estos cambios afectan solo a rasgos individuales de una construcción y no resultan en una nueva construcción, que sería la creación de un emparejamiento de una nueva forma y un nuevo significado (Traugott and Trousdale 2013: 1, 22, 26 y passim; Traugott 2015). Sin embargo, si la extensión semántica de la perífrasis fuera acompañada de un cambio estructural, o sea un cambio en su forma, de acuerdo con el marco teórico de la gramática de construcciones nos encontraríamos con una nueva construcción. Por ello, el examen de una serie de rasgos estructurales será el tema de la sección 4.

\section{ANÁLISIS SINTÁCTICO}

Habiendo constatado en la sección anterior que en el español de México la perífrasis con andar está en un estado de gramaticalización ya avanzado, en esta sección examinamos qué repercusiones tiene el proceso de gramaticalización de la perífrasis en el plano sintáctico. Para ello, nos centramos en los siguientes criterios sintácticos, que distintos estudios consideran clave para definir los procesos de gramaticalización en general y de las perífrasis en particular (cf. Garachana Camarero 2017: 35-80; Lehmann 1985; Myhill 1988; Torres Cacoullos 1999a): 
1. la adyacencia de andar y el gerundio;

2. la fijación del orden de andar y el gerundio;

3. la subida de clíticos;

4. la coordinación de los gerundios.

Para el análisis de las propiedades estructurales de la perífrasis utilizamos el corpus $\mathrm{CDH}$, puesto que proporciona datos diacrónicos suficientes, que nos permiten rastrear posibles cambios en la estructura sintáctica de andar + GER a lo largo del tiempo.

\subsection{LA ADYACENCIA DE ANDAR Y EL GERUNDIO}

Lehmann (1985) argumenta que la autonomía de un signo está determinada por el grado de libertad con el que se puede usar, de manera que cuanto más libre sea su uso tanto más autónomo es. Por otra parte, al gramaticalizarse un signo, disminuye su autonomía, de tal forma que el grado de autonomía es inversamente proporcional al grado de gramaticalización de un signo. Uno de los criterios para medir la autonomía del signo, según Lehmann (1985), es la variabilidad del mismo, en el supuesto de que más variabilidad implica mayor autonomía. Con el término de variabilidad sintagmática el autor se refiere a la posibilidad de moverse un signo de un sitio a otro dentro de cierta construcción, que es lo que interesa al estudiar la variabilidad de los componentes que integran la perífrasis de andar.

Los datos presentados hasta ahora se basaban en casos en que el verbo andar y el gerundio aparecían adyacentes, sin que se insertara ningún otro constituyente entre los dos. Sin embargo, también se documentan ocurrencias en que ambos componentes de la perífrasis están separados por uno o varios constituyentes o palabras. Los ejemplos (11) y (12) ilustran esta situación.

(11) (...) mas como los confesores son pocos, andan los Indios de un monasterio en otro buscando quien los confiese (...). (Fray Toribio de Benavente, Historia de los Indios de la Nueva España, 1536, CDH)

(12) ¿Conque anda en Roma escribiendo un reportaje, eh? (Arturo Azuela, El tamaño del infierno, 1973, CDH)

Si los datos comprobaran que el auxiliar y el gerundio ocurrieran mayoritariamente en adyacencia, podríamos tomarlo como un indicio de que el grado de autonomía de los componentes de la perífrasis es relativamente bajo, y, por consiguiente, que el grado de gramaticalización de la construcción es relativamente alto. 
La Tabla 9 arroja los datos acerca de la frecuencia relativa de los casos adyacentes frente a los separados.

\begin{tabular}{|l|r|r|r|}
\hline siglo & adyacentes & separados & total \\
\hline xvi & $74,5 \%(184)$ & $25,5 \%(63)$ & $100 \%(247)$ \\
\hline xvii & $60,9 \%(70)$ & $39,1 \%(45)$ & $100 \%(115)$ \\
\hline xviii & $54,5 \%(6)$ & $45,5 \%(5)$ & $100 \%(11)$ \\
\hline xix & $66,7 \%(18)$ & $33,3 \%(9)$ & $100 \%(27)$ \\
\hline xx & $85,4 \%(76)$ & $14,6 \%(13)$ & $100 \%(89)$ \\
\hline total & $72,4 \%(354)$ & $27,6 \%(135)$ & $100 \%(489)$ \\
\hline
\end{tabular}

Tabla 9: Frecuencia relativa de andar + GER adyacentes y separados en textos mexicanos por siglo $(\mathrm{CDH})$

Como se puede ver en la Tabla 9, los casos de adyacencia son más frecuentes que los casos de separación en todos los siglos. La diferencia más grande se observa en el siglo xx, con el 85,4\% de casos adyacentes frente al 14,6\% de casos de separación. Parece, por lo tanto, que en la lengua actual de México el auxiliar y el gerundio carecen en gran medida de variabilidad y, por ello, de autonomía.

\subsection{LA FIJACIÓN DEL ORDEN DE ANDAR Y EL GERUNDIO}

Además de la adyacencia de los dos componentes de la perífrasis, la pérdida de variabilidad sintagmática se observa también en la fijación de los mismos en determinada posición. Según Lehmann (1985), si un elemento ocupa una posición fija (fixed slot) y (ya) no puede cambiar de sitio libremente, estamos ante un caso de gramaticalización fuerte.

No cabe duda de que en español contemporáneo el auxiliar andar y el gerundio ocupan una posición fija el uno respecto del otro, en el sentido de que la forma verbal de andar siempre precede al gerundio. Sin embargo, si a lo largo de la historia del español se documentaran ocurrencias del orden inverso de la perífrasis, es decir, con el gerundio precediendo al auxiliar, estas constituirían un indicio de que andar + GER todavía no estaría gramaticalizado del todo.

El subcorpus mexicano $\mathrm{CDH}$ registra seis casos en total de dicho orden inverso. El más reciente, de principios del siglo XVII, es el que se reproduce en (13) y que proviene de una obra en verso. Por eso, no se descarta que este 
género, que suele permitir un orden de palabras más libre, sea responsable del orden inverso de andar y el gerundio.

(13) Yo me aparto, y a un mendigo, que limosna entre los coches pidiendo andaba en el río. (Juan Ruiz de Alarcón, Los favores del mundo, $1618, \mathrm{CDH})$

Los cinco casos restantes provienen de la Historia general de las cosas de Nueva España (1576), de Fray Bernardino de Sahagún, y presentan todos la misma combinación de gerundio y forma de andar. Considérese el ejemplo (14).

(14) Yendo andando, un agua hacia riba, dijeron unos a otros: ... (Anónimo, Relación de las ceremonias y rictos y población y gobernación de los indios de la provincia de Mechuacán, 1541, CDH)

Cabe destacar, sin embargo, la posibilidad de que los ejemplos como (14), en realidad, sean ocurrencias de la perífrasis de $i r+$ GER, que en tal caso presentarían el orden común. De todas maneras, la escasez de casos y la cuestionabilidad de la mayor parte de ellos, nos lleva a concluir que en el español de México el orden inverso de la perífrasis con andar en la actualidad es inexistente y nunca ha sido una opción viable.

\subsection{LA SUBIDA DE CLÍTICOS}

La subida de clíticos se da en construcciones verbales que constan de un verbo finito y otro verbo no finito, tal como es el caso, entre otros, con las perífrasis verbales. En tales casos, el pronombre átono que complementa a la forma no finita puede colocarse delante de la forma finita, "subiendo" a la posición a la izquierda de esta. Dicha subida, sin embargo, solo puede producirse si se perciben la forma finita y no finita como un conjunto o unidad inseparable. (cf. Keniston 1936: 163; Lenz 1925: 385; Myhill 1988; Torres Cacoullos 1999a) 24. Según la RAE y ASALE (2009: 2200), "la anteposición del pronombre átono permite reconocer la perífrasis, ya que los complementos del gerundio no pasan a ser proclíticos del verbo flexionado si la construcción no es perifrástica".

24 Ya señaló Cuervo (1994 [1886]: 460), al tratar el verbo andar, que los pronombres complementos del gerundio podían anteponerse al verbo andar. 
Podemos evaluar el grado de unión entre el auxiliar y el gerundio, por lo tanto, de acuerdo con la posición de los clíticos respecto de una u otra forma verbal. Para el presente cálculo hemos categorizado la posición de los pronombres átonos según se coloquen detrás del gerundio o aparezcan delante de la forma verbal de andar, posiciones que quedan ilustradas en los ejemplos (15) y (16), tanto para los casos adyacentes como para los casos de separación (véase también el apartado 4.1.) ${ }^{25}$.

(15) (...) y para que los religiosos tengan qüenta con ellos y no anden buscando los por los montes, ... (Fray Pedro de Gante, Carta de Fray Pedro de Gante al Emperador D. Carlos, 1552, CDH)

(16) $\mathrm{Y}$ aunque se te pone este precepto, no te andan guardando para que no lo bevas. (Fray Bernardino de Sahagún, Historia general de las cosas de Nueva España, 1576, CDH)

Los resultados de este cálculo se exponen en la Tabla 10.

\begin{tabular}{|l|r|r|r|r|r|r|}
\hline & \multicolumn{3}{|c|}{ adyacentes } & \multicolumn{3}{c|}{ separados } \\
\hline siglo & anteposición & posposición & total & anteposición & posposición & total \\
\hline xvi & $57,9 \%(11)$ & $42,1 \%(8)$ & $100 \%(19)$ & $30 \%(3)$ & $70 \%(7)$ & $100 \%(10)$ \\
\hline xvii & $33,3 \%(3)$ & $66,7 \%(6)$ & $100 \%(9)$ & $0 \%(0)$ & $100 \%(8)$ & $100 \%(8)$ \\
\hline xviii & $100 \%(1)$ & $0 \%(0)$ & $100 \%(1)$ & - & - & - \\
\hline xix & - & - & - & $0 \%(0)$ & $100 \%(3)$ & $100 \%(3)$ \\
\hline xx & $66,7 \%(10)$ & $33,3 \%(5)$ & $100 \%(15)$ & $100 \%(2)$ & $0 \%(0)$ & $100 \%(2)$ \\
\hline total & $56,8 \%(25)$ & $43,2 \%(19)$ & $100 \%(44)$ & $21,7 \%(5)$ & $78,3 \%(18)$ & $100 \%(23)$ \\
\hline
\end{tabular}

Tabla 10: Frecuencia relativa de la posición del clítico con andar + GER adyacentes y separados en textos mexicanos por siglo (CDH)

25 El corpus contiene 13 casos de adyacencia y 2 casos de separación en los que el clítico, si bien se ha desplazado hacia la izquierda, se ha colocado detrás de la forma verbal de andar, como en

(i) (...) con el cuidado que de su vida y de los de su compañía tinie, andábase paseando por dentro de su aposento, e vio una puerta ... (CDH, Andrés de Tapia, Relación hecha por el señor Andrés de Tapia, sobre la conquista de México, 1525)

Como estos ejemplos presentan subida de clíticos pero difieren de los en que el clítico termina encontrándose a la izquierda del auxiliar, los hemos excluido del presente cálculo. 
De la Tabla 10 se desprende que, si el predicado tiene un complemento expresado por un clítico, este, en general, se coloca más frecuentemente delante del auxiliar que detrás del gerundio si los dos componentes aparecen en adyacencia; en los siglos XVI, XVIII y XX el porcentaje de clíticos antepuestos es más alto que el de clíticos pospuestos.

Además, y quizá más significativo aún, los datos de la Tabla 10 muestran que en caso de que el auxiliar y el gerundio aparezcan separados por otra(s) palabra(s) o constituyente(s), el clítico se coloca casi exclusivamente detrás del gerundio, salvo tres casos en el siglo xvi y dos casos en el siglo xx. En todos esos casos de anteposición la separación es relativamente limitada, con intercalación de adverbios simples en los siglos XVI y Xx (siempre, ya, asi y alli), y solo un adverbio compuesto (de continuo) en el siglo XVI. $\mathrm{Si}$ se intercalan más palabras o constituyentes más largas (en mi compañia, muchos días por las casas de los indios), no se produce la subida de clíticos en ningún caso.

Por lo tanto, tal como se esperaba, la subida de clíticos se produce casi únicamente si el auxiliar y el gerundio están en adyacencia; en casos de separación los dos componentes de la perífrasis no se perciben como un conjunto, de manera que el clítico no puede desplazarse a la posición delante del auxiliar. Además, como también muestra la Tabla 10, los clíticos se anteponen al auxiliar desde las primeras ocurrencias de andar + GER en el español mexicano, es decir, a partir del siglo XVI, lo que sugiere que la perífrasis empezó a gramaticalizarse en una época relativamente temprana.

\subsection{LA COORDINACIÓN DE LOS GERUNDIOS}

En nuestros datos ocurre con cierta frecuencia que el verbo andar selecciona dos gerundios que están enlazados por una de las conjunciones coordinantes $y(e)$ u $o$, o simplemente yuxtapuestos y separados por una coma. Se trata de ejemplos como (17) a (20).

(17) (...) e vieron salir de sus casas a los dichos fator e veedor, andando acomunando e llamando la gente de casa en casa. (Anónimo, Memoria de lo acaecido en esta ciudad después que el gobernador Hernando Cortés salió della, 1525, CDH)

(18) Todo el día andabas saltando y cantando en casa; ... (José Joaquín Fernández de Lizardi, La Quijotita y su prima, 1818, CDH)

(19) ¿Andava burlando o haziendo niñerías? (Fray Bernardino de Sahagún, Historia general de las cosas de Nueva España, 1576, CDH) 
(20) Mira que es el sacerdocio donde no ha de estar el ocio, sino siempre andar velando, entendiendo en su negocio. (Fernán González de Eslava, Coloquio quinto de los siete fuertes, $1580, \mathrm{CDH}$ )

Torres Cacoullos (1999a), al comparar el empleo de estos gerundios coordinados en perífrasis de gerundio con estar e ir en el español antiguo y en el español actual de la Ciudad de México, concluye que la frecuencia de este tipo de construcciones perifrásticas disminuyó destacadamente, siendo casi inexistente en el español mexicano actual. Según ella, esta disminución refleja la relación más estrecha entre el auxiliar y el gerundio y, consiguientemente, podría tomarse como señal de la (mayor) gramaticalización de la perífrasis.

En la Tabla 11 se presentan los datos cuantitativos relevantes, es decir los casos de la perífrasis de andar con dos (o más) gerundios coordinados frente a los casos de la perífrasis con un solo gerundio. Hemos incluido en el grupo de los gerundios coordinados 13 casos en que se ha(n) insertado otro(s) constituyentes entre los dos, como es el caso en los ejemplos (21) y (22).

(21) Cuando de noche vía alguno unas fantasmas que ni tienen pies ni cabeça, las cuales andan rodando por el suelo y dando gemidos como enfermo, ... (Fray Bernardino de Sahagún, Historia general de las cosas de Nueva España, 1576, CDH)

(22) (...) creyó que andaría recorriendo la huerta, examinando sus flores $\mathrm{y}$ viendo los estragos del temporal. (Ignacio Manuel Altamirano, $E l$ Zarco: episodio de la vida mexicana en 1861-63, 1886, CDH)

\begin{tabular}{|l|r|r|r|}
\hline siglo & solo & coordinados & total \\
\hline xvi & $88,3 \%(218)$ & $11,7 \%(29)$ & $100 \%(247)$ \\
\hline xvii & $91,3 \%(105)$ & $8,7 \%(10)$ & $100 \%(115)$ \\
\hline xviii & $100 \%(11)$ & $0 \%(0)$ & $100 \%(11)$ \\
\hline xix & $85,2 \%(23)$ & $14,8 \%(4)$ & $100 \%(27)$ \\
\hline xx & $95,5 \%(85)$ & $4,5 \%(4)$ & $100 \%(89)$ \\
\hline total & $90,4 \%(442)$ & $9,6 \%(47)$ & $100 \%(489)$ \\
\hline
\end{tabular}

Tabla 11: Frecuencia relativa de andar + GER con un solo gerundio o dos gerundios coordinados en textos mexicanos por siglo $(\mathrm{CDH})$

La Tabla 11 muestra que a lo largo del tiempo se ha ido reduciendo la posibilidad de que la perífrasis seleccione más de un gerundio, del $11,7 \%$ en el siglo XVI al 4,5\% en el siglo Xx. El siglo XIX presenta el porcentaje de gerundios coordinados más alto, pero es de notar que tres de los cuatro casos en ese siglo provienen del mismo autor y que en el cuarto caso, 
presentado como ejemplo (22) aquí arriba, podría interpretarse el segundo y tercer gerundio (examinando y viendo, respectivamente) quizá también como complementos adverbiales que modifican la acción expresada por la perífrasis andaría recorriendo.

La baja frecuencia de las construcciones perifrásticas con dos gerundios coordinados, ya desde el siglo XVI, corrobora que la perífrasis de andar en el español mexicano está altamente gramaticalizada y que el proceso de gramaticalización comenzó relativamente temprano.

\section{RESUMEN Y CONCLUSIONES}

En el presente trabajo hemos estudiado el uso de la perífrasis andar + GER en el español de México. Un análisis de su frecuencia relativa en varios corpus tomando en cuenta no solo el dialecto mexicano, sino también el peninsular, ha puesto en evidencia que la construcción ocurre mucho más en aquel que en este, que dicha diferencia frecuencial se observa ya en los primeros documentos mexicanos y que se mantiene a través del tiempo. Los datos para el siglo xx apuntan a que en el español mexicano el uso de la perífrasis ha incrementado su uso sobre todo en épocas recientes.

Por otra parte, hemos comprobado que la frecuencia alta de andar + GER es un fenómeno típicamente mexicano, es decir que, si bien en varios otros dialectos del continente americano también se usa la perífrasis, ningún otro dialecto llega a exhibir frecuencias tan altas como en México. Asimismo, nuestros datos sugieren que la modalidad del habla influye en el uso de la perífrasis, puesto que la construcción resulta ser particularmente frecuente en la lengua hablada. Además, el hecho de que andar + GER tiene una frecuencia alta en blogs digitales corrobora la relación entre género textual y uso de la perífrasis, en el sentido de que la misma ocurre más en géneros de textos informales. Más en general, los resultados nos llevan a concluir que son las modalidades de lengua informales las que más favorecen el empleo de la perífrasis en el español de México.

Los análisis realizados en este trabajo, tanto en el plano semántico como en el sintáctico, nos permiten sacar una serie de conclusiones acerca de la gramaticalización de perífrasis de andar en el español de México. Si bien originalmente la combinación del verbo andar y el gerundio expresaba dos acciones simultáneas, ya en el siglo XVI andar + GER adquirió un valor aspectual y podía expresar una serie de matices pragmáticos, particularmente 
de determinación y empeño por parte del agente que realiza la acción o provoca la situación expresada por la perífrasis. Entre las clases de verbos con los que andar forma predicados de gerundio en el español de México destacan los que se componen de verbos de apoyo, es decir verbos semánticamente (semi)vacíos. Por contraste, en Nieuwenhuijsen (en prensa 2019) se comprueba que el español peninsular (todavía) predominan los verbos de desplazamiento en la perífrasis de andar. En México, por lo tanto, el efecto de persistencia (Hopper 1991: 22; cf. también Torres Cacoullos 2000: 4), o sea, el hecho de que huellas del significado léxico original de una construcción puedan imponer restricciones gramaticales en otra construcción evolucionada a partir de la primera, se ha atenuado mucho más que en España. La gramaticalización de andar + GER en el español de México se trasluce también en la posibilidad de juntarse la misma con verbos de estado, así como el surgimiento de entidades inanimadas en función de sujeto de la construcción. Por otra parte, la alta frecuencia relativa, si bien no sabemos si es la causa o la consecuencia del proceso de gramaticalización, sí sugiere que ya no nos encontramos con una combinación libre de palabras léxicas sino con una construcción fija.

Por lo que atañe a la estructura sintáctica, la gramaticalización de andar + GER está corroborada por la fijación casi absoluta de los dos componentes, tanto en lo relativo a su orden interno (el gerundio pospuesto al auxiliar) como en lo relativo a la estrecha unión de los dos componentes (adyacencia del auxiliar y el gerundio).

Además, otros dos indicios de la gramaticalización de la perífrasis los constituyen la subida de clíticos, que en el español mexicano se produce casi únicamente si el auxiliar y el gerundio están en adyacencia, o sea, cuando forman una unidad inseparable, y la disminución diacrónica y escasez actual en el español mexicano de casos en los que andar lleva dos gerundios coordinados, lo que apunta a una relación cada vez más estrecha entre el auxiliar y el gerundio.

Es interesante señalar que en el plano sintáctico andar + GER presenta menos variación dialectal, ya que en el español de España la perífrasis exhibe un comportamiento muy parecido al del español de México por lo que se refiere a los rasgos sintácticos que acabamos de comentar (Nieuwenhuijsen en prensa 2019). Los resultados del presente estudio, por lo tanto, parecen indicar que, en comparación con el español peninsular, es en la semántica donde andar + GER ha evolucionado y ha dado un paso más en el español mexicano.

La evolución de andar + GER aquí descrita se ajusta perfectamente a lo que en el marco de la gramática de construcciones se concibe como construccionalización, es decir el nacimiento de una nueva construcción, 
que consiste en la creación de un signo o una combinación de signos con una nueva forma y un nuevo significado (Traugott and Trousdale 2013: 1, 22, 26 y passim; Traugott 2015). Concretamente, hemos visto que la perífrasis a partir del esquema original de un verbo de movimiento (andar) modificado por otra acción (el gerundio) desarrolla un valor aspectual, pragmático, con el que se expresa determinación y empeño por parte del sujeto de la perífrasis. El surgimiento de ese nuevo significado va aparejado con una modificación en la forma, es decir, la fijación del orden del auxiliar y el gerundio-siempre adyacentes y siempre con el auxiliar en primer lugar.

El presente trabajo recalca la importancia del enfoque diatópico en estudios sobre las perífrasis verbales en particular y sobre procesos de gramaticalización en general. El caso de andar + GER revela que una construcción, en apariencia idéntica en dos dialectos, puede encontrarse en un estado de gramaticalización más o menos avanzado según el dialecto específico. El proceso de gramaticalización, por lo tanto, aunque se caracterice por una serie de etapas más bien generales y se desarrolle de acuerdo con ciertas pautas más o menos similares para toda forma o construcción que se gramaticalice, puede acelerarse (o refrenarse) dependiendo del entorno diatópico en el que tiene lugar.

\section{REFERENCIAS BIBLIOGRÁFICAS}

\section{BASES DE DATOS}

ADESSE. Base de datos de verbos, alternancias de diátesis y esquemas sintáctico-semánticos del español (Universidade de Vigo). http://webs.uvigo.es/adesse/ [Consulta mayo de 2018].

Corpus del Español del Siglo XXI (CORPES XXI). http://web.frl.es/CORPES/view/ inicioExterno.view [Consulta febrero de 2019].

Corpus del Español Mexicano Contemporáneo (CEMC). http://www.corpus.unam.mx:8080/ cemc/ [Consulta febrero de 2019].

Corpus del Español: Web/Dialectos (CdE/Web). https://www.corpusdelespanol.org/web-dial/ [Consulta enero de 2019].

Corpus del Nuevo Diccionario Histórico del Español (CDH). http://www.rae.es/recursos/ banco-de-datos/cdh [Consulta enero de 2019].

Corpus del Nuevo Diccionario Histórico del Español. Manual de consulta en línea. http:// web.frl.es/CNDHE/org/publico/pages/ayuda/ayuda.view [Consulta enero de 2019].

Corpus Diacrónico y Diatópico del Español de América (Cordiam). http://www.cordiam.org/ [Consulta enero de 2019].

Corpus Gradia (GRADIA). http://Gradiadiacronia.wixsite.com/Gradia/ corpus-Gradia [Consulta diciembre de 2017]. 


\section{BIBLIOGRAFÍA}

Alonso, Amado. 1951. Sobre métodos: construcciones con verbos de movimiento en español. En Amado Alonso, Estudios lingüísticos. Temas españoles, pp. 230-287. Madrid: Gredos.

BYBEe, JoAn. 2003. Mechanisms of change in grammaticalization: The role of frequency. En Joseph, Brian D. y Richard D. Janda (eds.). The Handbook of Historical Linguistics, pp. 602-623. Malden: Blackwell.

Bybee, JoAn y Rena Torres Cacoullos. 2009. The role of prefabs in grammatization. En Roberta Corrigan, Edith A. Moravcsik, Hamid Ouali y Kathleen M. Wheatley (eds.). Formulaic Language: Distribution and Historical Change, Vol. I, pp. 187-217. Ámsterdam/Philadelphia: John Benjamins.

Camus Bergareche, Bruno. 2004. Perífrasis verbales y expresión del aspecto en español. En Luis García Fernández y Bruno Camus Bergareche (eds.). El pretérito imperfecto, pp. 511-572. Madrid: Gredos.

Coseriu, Eugenio. 1977. Sobre las llamadas "construcciones con verbos de movimiento: un problema hispánico. En Eugenio Coseriu, Estudios de lingüística románica, pp. 70-78. Madrid: Gredos.

Cotton, Eleonor Greet y John M. Sharp. 1988. Spanish in the Americas. Washington: Georgetown University Press.

Covarrubias Horozco, Sebastián de. 2006 [1611]. Tesoro de la lengua castellana o española. Madrid: Iberoamericana/Vervuert, 2006.

Crego García, María Victorina. 1994. Construcciones libres vs. Perífrasis verbales en los verbos de movimiento del español medieval. Verba: Anuario galego de filoloxía 21: 207-224.

Cuervo, Rufino, José. 1994 [1886]. Diccionario de construcción y régimen de la lengua castellana. Bogotá: Instituto Caro y Cuervo.

Diк, Simon C. 1997. The Theory of Functional Grammar. Part 1 The Structure of the Clause. Segunda edición editada y revisada por Kees Hengeveld. Berlín/Nueva York: Mouton de Gruyter.

Fente Gómez, Rafael, Jesús Fernández Álvarez y Lope G. Feijóo. 1972. Perífrasis verbales. Madrid: SGEL.

Fernández de CAStro, Félix. (1999). Las perifrasis verbales en el español actual. Madrid: Gredos.

2003. El lugar de las perífrasis verbales en la descripción de las lenguas: los verbos auxiliares y la determinación del verbo. En Claus D. Pusch y Andreas Wesch (eds.). Verbalperiphrasen in den (ibero-) romanischen Sprachen/ Perifrasis verbals en les llengües (ibero-)romániques/ Perífrasis verbales en las lenguas (ibero-)románicas, pp. 11-22. Hamburgo: Helmut Buske Verlag,

Garachana Camarero, Mar (ed.). 2017. La gramática en la diacronía. La evolución de las perifrasis verbales modales en español. Madrid/Fráncfort: Iberoamericana/Vervuert.

Garcés Gómez, María Pilar. 1992. Valores y usos de algunas construcciones verbales en español. En Manuel Ariza, Rafael Cano, José María Mendoza y Antonio Narbona (eds.). Actas del II congreso internacional de historia de la lengua española, Vol. 1, pp. 437-444. Madrid: Arco Libros [en línea]. Disponible en:

http://www.cervantesvirtual.com/descargaPdf/valores-y-usos-de-algunas-contruccionesverbales-en-espaol-0/ [Consulta mayo de 2018].

García Fernández, Luis (dir.). 2006. Diccionario de perifrasis verbales. Madrid: Gredos. (2012). Las perifrasis verbales. Madrid: Castalia.

García GonZÁlez, Javier. 1992. Perífrasis verbales. Madrid: SGEL. 
GARCía PADRÓn, Dolores. 1990. En torno al llamado "proceso de desemantización". Filología Románica 7: 241-253.

Glare, Peter G.W. (ed.). 1968. Oxford Latin Dictionary. Oxford: At the Claredon Press.

Gómez Torrego, Leonardo. 1988. Perifrasis verbales. Madrid: Arco/Libros.

1999. Los verbos auxiliares. Las perífrasis verbales de infinitivo. En Ignacio Bosque y Violeta Demonte (eds.). Gramática descriptiva de la lengua española, pp. 3323-3389. Madrid: Espasa Calpe.

Hamplová, Sylvia. 1968. Acerca de la manera de acción y el problema de su expresión mediante las perífrasis verbales en español. Philologica Pragensia 11: 209-231.

Haspelmath, Martin. 2000. Periphrasis. En Geert E. Booij, Christian Lehmann y Joachim Mugdan (eds.). en colaboración con Wolfgang Kesselheim y Stavros Skopeteas. Morphology: An International Handbook on Inflection and Word-Formation, pp. 654-664. Berlin/Boston: De Gruyter Mouton (libro electrónico).

Heine, Bernd. 2003. Grammaticalization. En: Brian Joseph y Richard Janda (eds.). The Handbook of Historical Linguistics, pp. 573-60. Oxford: Blackwell Publishing Ltd.

Hilpert, Martin. 2012. Corpus-based approaches to constructional change. En Thomas Hoffmann y Graeme Trousdale (eds.). The Oxford Handbook of Construction Grammar, pp. 458-475. Oxford: Oxford University Press.

Hopper, Paul J. 1991. On some principles of grammaticization. En Elizabeth Closs Traugott, y Bernd Heine (eds.). Approaches to Grammaticalization. Focus on Theoretical and Methodological Issues, Vol. I, pp. 17-35. Ámsterdam/Philadelphia: John Benjamins.

y Elizabeth Closs Traugott. 2003. Grammaticalization. Cambridge: Cambridge University Press.

Keniston, Hayward. 1936. Verbal aspect in Spanish. Hispania 19 (2): 163-176.

1937. The Syntax of Castilian Prose. The Sixteenth Century. Chicago: The University of Chicago Press.

Koch, Peter y Wulf Oesterreichter. 1990. Gesprochene Sprache in der Romania: Französich, Italienisch, Spanish. Tübingen: Max Niemeyer Verlag.

Lehmann, Christian. 1985. Grammaticalization: synchronic variation and diachronic change. Lingua e Stile 20: 303-318.

Lenz, Rodolfo. 1925. La oración y sus partes. Madrid: Publicaciones de la Revista de Filología Española.

Llorente Vigil, Covadonga. (1999). Las perifrasis verbales. Salamanca: Colegio de España.

Lomborg, Stine. 2009. Navigating the Blogosphere: Towards a Genre-based Typology of Weblogs. First Monday 14 (5) [en línea]. Disponible en: https://firstmonday.org/article/ view/2329/2178 [Consulta enero de 2019].

Luna Trail, Elizabeth. 1980. Sintaxis de los verboides en el habla culta de la Ciudad de México. México: Unversidad Nacional Autónoma de México.

Lyer, Stanislav. 1932. La syntaxe du gérondif dans le "Poema del Cid". Revista de filología española XIX (1): 1-46.

1934. Syntaxe du gérondif et du participe présent dans les langues romanes. París: E. Droz.

Mair, Christian. 2011. Grammaticalization and corpus linguistics. En Heiko Narrog y Bernd Heine (eds.). The Oxford Handbook of Grammaticalization, pp. 239-250. Oxford: Oxford University Press.

MARKIČ, JASMINA. 2006. Valores y usos de las perífrasis verbales de gerundio con los auxiliares ir, andar y venir. Linguistica 46 (1): 243-250.

Matthies, Werner. 1933. Die aus den intransitiven Verben der Bewegung und dem Partizip des Perfekts gebildeten Umschreibungen im Spanischen. Tesis doctoral. Jena: W. Gronau. 
Morera, Marcial. 1991. Diccionario crítico de las perifrasis verbales del español. Puerto del Rosario: Servicio de publicaciones del Excmo. Cabildo Insular de Fuerteventura.

Myнill, John. 1988. The grammaticalization of auxiliaries: Spanish clitic climbing. Proceedings of the Fourteenth Annual Meeting of the Berkeley Linguistics Society 14: 352-363.

NieuWenhuiJsen, Dorien (en prensa 2019). Anden diciendo esto y lo otro: evolución diacrónica de la perífrasis $<$ andar + gerundio $>$. Categorías semiléxicas. Haciendo balance entre el contenido léxico y la función gramatical, número monográfico de la Revista Española de Lingüistica.

Oesterreicher, Wulf. 1996. Lo hablado en lo escrito. Reflexiones metodológicas y aproximación a una tipología. En Thomas Kotschi, Wulf Oesterreicher y Klaus Zimmermann (eds.). El español hablado y la cultura oral en España e Hispanoamérica, pp. 317-340. Madrid/Fráncfort: Iberoamericana/Vervuert.

Olbertz, Hella. 1998. Verbal Periphrases in a Functional Grammar of Spanish. Berlín/ Nueva York: Mouton de Gruyter.

Porroche Ballesteros, Margarita. 1990. Aspectos de la atribución en español. Zaragoza: Libros Pórtico.

RAE y ASALE. 2009. Nueva gramática de la lengua española. Madrid: Espasa Libros.

2015. Diccionario de la lengua española [en línea]. Disponible en: http://dle.rae. es/ [Consulta enero de 2019].

Roca Pons, José. 1958. Estudios sobre periffrasis verbales del español. Madrid: CSIC.

Rodríguez Molina, Javier y Álvaro Octavio de Toledo y Huerta. 2017. La imprescindible distinción entre texto y testimonio: el CORDE y los criterios de fiabilidad lingüística. Scriptum Digital 6: 5-68 [en línea]. Disponible en: http://www.scriptumdigital.org/ documents/03_SD06_01_Octavio_Molina.pdf [Consulta enero de 2019].

SARRAZIN, Sophie. 2011. Una semántica del espacio al servicio del aspecto: estar, ir, venir, andar, auxiliares de perífrasis verbales en español. En Juan Cuartero Otal, Luis García Fernández y Carsten Sinner (coords.). Estudios sobre perifrasis y aspecto, pp. 180-198: Múnich, Peniope.

Sedano, Mercedes. 2000. La perífrasis de gerundio en Caracas y otras ciudades hispanohablantes. NRFH 48 (2): 253-274.

Sindoni, Maria Grazia. 2013. Spoken and Written Discourse in Online Interactions. Nueva York: Routledge.

Squartini, Mario. 1998. Verbal Periphrases in Romance. Aspect, Actionality, and Grammaticalization. Berlín/Nueva York: Mouton de Gruyter.

Torres Cacoullos, Rena. 1999a. Construction frequency and reductive change: Diachronic and register variation in Spanish clitic climbing. Language Variation and Change 11: 143-170. 1999b. Variation and grammaticization in progressives: Spanish -ndo constructions. Studies in Language 23 (1): 25-59.

2000. Grammaticalization, Synchronic Variation, and Language Contact: A Study of Spanish Progressive -ndo Constructions. Ámsterdam/Philadelphia: John Benjamins. 2001. From lexical to grammatical to social meaning. Language in Society 30 (3): 443-478.

2012. Grammaticalization through inherent variability. The development of a progressive in Spanish. Studies in Language 36 (1): 73-122.

Traugott, Elizabeth Closs. 2010. Grammaticalization. En Silvia Luraghi y Vit Bubenik (eds.). Bloomsbury Companion to Historical Linguistics, pp. 271-285. Londres: Bloomsbury [libro electrónico]. 
2015. Toward a coherent account of gramatical constructionalization. En: J. Barðdal, E. Smirnova, L. Sommerer y S. Gildea (eds.). Diachronic Construction Grammar. Ámsterdam/Philadelphia: John Benjamins, pp. 51-79.

Traugott, Elizabeth Closs y Graeme Trousdale. 2013. Constructionalization and Constructional Changes. Oxford: Oxford University Press [libro electrónico].

VillalPando-QuiñoneZ, Jesús. s.a. Se anda gramaticalizando en México? El verbo auxiliar andar con gerundio (borrador) [en línea]. Disponible en: https://www.academia. edu/6123806/ANDAR_gerund_in_Mexican_Spanish_A_grammaticalized_Auxiliary_ construction [Consultado mayo de 2018].

Yllera Fernández, Alicia. 1980. Sintaxis histórica del verbo español: Las perifrasis medievales. Zaragoza: Departamento de Filología Francesa, Universidad de Zaragoza.

1999. Las perífrasis verbales de gerundio y participio. En Ignacio Bosque y Violeta Demonte (eds.). Gramática descriptiva de la lengua española, pp. 3391-3441. Madrid: Espasa Calpe. 